\title{
Improving retention for all students, studying mathematics as part of their chosen qualification, by using a voluntary diagnostic quiz
}

Carol Calvert, The Open University, Milton-Keynes, UK. Email: carol.calvert@open.ac.uk Rachel Hilliam, The Open University, Milton-Keynes, UK. Email: rachel.hilliam@open.ac.uk Juliet Coleman, The Open University, Milton-Keynes, UK. Email: juliet.coleman@open.ac.uk

\begin{abstract}
This case study demonstrates the issues and advantages in encouraging students to take responsibility for their learning and to be better prepared both in terms of knowledge and expectations for their study. The study outlines the improvement in retention achieved when students were encouraged to use a voluntary diagnostic quiz on a first year university mathematics module. Initially the power of the diagnostic quiz, in predicting future success on the module, was identified using predictive analytics. Students were contacted by experienced Education Guidance staff who encouraged them to take the quiz prior to course start with the aim of using their results to steer them to start on the "right" course. The diagnostic quiz total score was made available to the student's course tutor prior to course start to enable further tailoring of support to individual students. Early indications show an improvement in early module retention. The module in this case study was for distance learning students on an open access mathematics course.
\end{abstract}

Keywords: diagnostic quiz, predictive analytics, retention, distance education, learning analytics.

\section{Introduction}

The Open University UK (OUUK) is a distance learning environment with an open entry policy where the vast majority of the undergraduates are studying part-time. Students are initially advised by a generalist advice service supplemented later by an education guidance team specialising in their chosen curriculum. Students are supported during their study by a local personal tutor who is an Associate Lecturer at OUUK. Powerful statistical analysis, using predictive analytic techniques, has recently added to the evidence base upon which to base advice and support. There is an increased amount of this type of work, called learning analytics, in the University.

OUUK allows its students considerable flexibility in managing their pace and volume of study together with their qualification route. OUUK modules are typically 30 or 60 credits of study with one credit being the equivalent of 10 hours of study. Three hundred and sixty credits are required for an honours undergraduate degree. OUUK Level 1 study is broadly equivalent to first year undergraduate study. There are three mathematics modules at Level 1 and all are 30 credit modules. They are not only studied by Mathematics students as they also form compulsory or optional elements of a range of qualifications from other disciplines like Engineering and Science.

"Essential Mathematics 1" (MST124) is the standard start mathematics module. It is a core option for around 20 qualifications and it is compulsory on over 40 qualifications. The module has a poor pass rate and it is possible for a number of qualifications for students to study an alternative starting module "Discovering Mathematics" (MU123). There is a high quality diagnostic quiz "Are you ready for MST124" (OUUK, 2016) which is underused by students and its power, in terms of helping students with MST124, is underrated. The quiz is designed to be ideally taken pre-registration in order to aid module choice and as such is freely available to both current and prospective students. 
The approach taken in this case study was to first demonstrate the potential of the quiz as a predictor variable for future success on MST124. The evidence was then shared with staff for use in an advisory conversation with students prior to module start. Students with low or no quiz results were contacted and encouraged to do the quiz or advised about options if they had a low score.

Calvert (2014) identified a core set of explanatory variables linked to student success at different points, or milestones, in a student journey. The same approach has been adapted to apply specifically to MST124 with the addition of one specific explanatory variable: the results of the diagnostic quiz for that module.

\section{Mathematics Diagnostic quizzes}

Mathematics diagnostic quizzes are widely used to establish the mathematics ability of students preparing to study mathematics and non-mathematics qualifications. Batchelor (2004), provides a literature review and a specific example of a mathematical diagnostic test for Pharmacy undergraduates. Many students who take the OUUK standard start mathematics MST124 module are not mathematicians: most are from other disciplines including a large group of engineers.

The Engineering Council (2000) commissioned work on the teaching of mathematics for Engineers, and this included looking at mathematics diagnostic quizzes in use at several universities. The Engineering Council had four key recommendations of which the first two were:

1. Students embarking on mathematics-based degree courses should have a diagnostic (maths) test on entry;

2. Prompt and effective support should be available to students whose mathematical background is found wanting by the tests.

OUUK has a long tradition of using diagnostic quizzes prior to entry level study. As a distance learning institution the OUUK does not have students physically on campus, this provides challenges both in terms of encouraging students to undertake the quiz and then providing the support to enable students to understand the implications of their chosen study module based on their quiz score.

Lockwood (1989) evaluated the effectiveness of such OUUK diagnostic materials including a Mathematics Preparation Pack which included a diagnostic quiz. Over $90 \%$ of the students he surveyed self-reported that they did the quiz, but only $14 \%$ decided to study further material recommended to improve their level of preparation for their chosen course. Centrally held data suggested that 7\% of 2014 MST124 October entrants had taken the MST124 Diagnostic Quiz. However this is an underestimate as it does not take into account students who take the quiz on the OUUK external website prior to registering or elect to take a paper rather online version. In these cases it is not possible to link the quiz score to the student and therefore not included in the $7 \%$.

Donavan \& Loch (2013) describe one way in which active learning can be achieved in large firstyear mathematics classes. They also provide a literature review of active learning and highlight that "in active learning approaches, students take responsibility for their learning". MST124 is potentially an entry level module and the diagnostic quiz "Are you ready for MST124" is very much in the spirit of active learning with immediate feedback and with students retaining the decision about whether to take the MST124 module or transfer to MU123 or, indeed, study a different module completely. The quiz consists of 20 questions and each question can be attempted three times before the correct answer is supplied. The questions cover algebraic manipulation, solving equations, factorisation and 
expansion and basic trigonometry. A first correct answer scores 5 points, a correct answer on the second attempt 3.33 and on the third attempt 1.67. After two incorrect attempts a hint is given and a full answer is given after a third incorrect attempt.

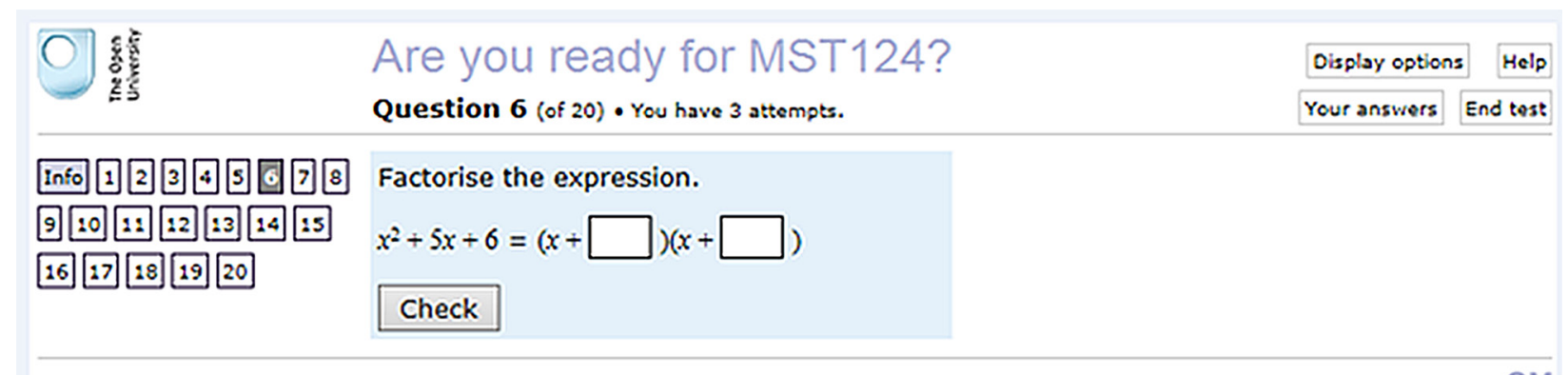

Figure 1: Example of a diagnostic quiz question for MST124

\section{Demonstrating the usefulness of the quiz}

OUUK have a statistical model based on logistic regression which identifies key variables which can be used to predict student success at different milestones in their OUUK student journey (Calvert, 2014). The model is very flexible and runs with a standard set of thirty possible variables from which the most statistically significant factors at particular milestones are selected. The model was adapted in the case study to run specifically against MST124 and with new variables relating to whether the quiz was taken or not (quiz_flag) and the quiz score.

The quiz is optional and hence, merely by taking the quiz, it indicates a measure of engagement with study by the student. Additionally, it is a relatively direct measure of ability in mathematics and hence potentially a measure of mathematical success. There are therefore two strong theoretical reasons to believe the quiz would be closely associated with success on the module. The quiz is available to be taken prior to module start and it is therefore possible to include the quiz results in runs of the model well before students start study on MST124.

The model, running on data available before students started on the October 2014 presentation, identified that simply taking the quiz, was a significant variable in predicting if the student would be present at crucial fee points part way through the module. A fee point is where English students become liable to the English student loan company for a percentage of their study fees. For the first fee point the quiz_flag was one of nine variables identified. For the second fee point it was one of eleven variables and for the third fee point one of twelve variables. Students complete MST124 when they sit the examination and quiz_flag was one of fourteen variables identified as predicting completion and one of eleven useful in predicting passing the module. 


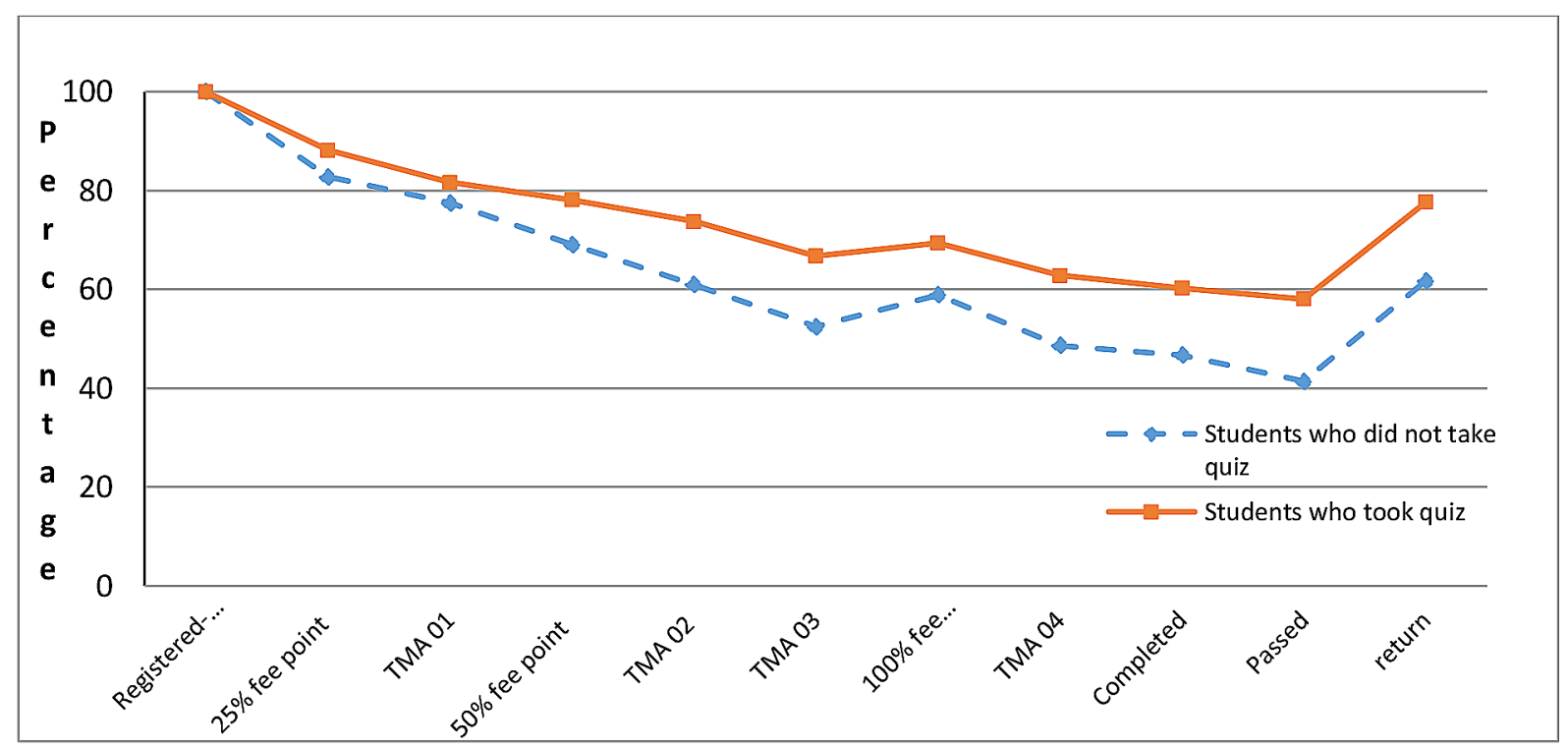

Figure 2: Percentage of registered students on October 2014 presentation of MST124 who were present at key points during the module: by those who had taken quiz and those who had not.

For presentation purposes, rather than look at the logistic regression probability outputs, it proved helpful to separately plot the paths of students who had taken the quiz and those who had not. Figure 2 shows the percentage of the original group, for those who took the quiz and those who did not in the October 2014 cohort, who were present at the fee points. In addition Figure 2 also shows the percentage of students submitting each of the four Tutor Marked Assignments (TMA). Students passively withdraw during the module and this is frequently evidenced by the student failing to submit a TMA. It is therefore typical that to see more students apparently still registered at the $100 \%$ fee point than the numbers who submitted TMA03 despite the $100 \%$ fee point being after the TMA03 due date.

\section{Uptake of the diagnostic quiz}

MST124 was introduced in 2014 and the MST124 diagnostic quiz is designed to help students identify areas where they may experience difficulty. Table 1 shows that only a very low percentage of students took the quiz in October 2014. Hence the first issue to be addressed was to encourage students to take the quiz so that the student could be advised accordingly.

Table 1 Numbers and percentages registered on MST124 at module start who had a quiz score (October 2014 and October 2015)

\begin{tabular}{|l|l|l|l|}
\hline & $\begin{array}{l}\text { Number students at } \\
\text { module start }\end{array}$ & $\begin{array}{l}\text { Number of those registered } \\
\text { who had taken quiz }\end{array}$ & $\begin{array}{l}\text { Percentage of those registered } \\
\text { with quiz score }\end{array}$ \\
\hline $\begin{array}{l}\text { Oct } \\
2014\end{array}$ & 2686 & 199 & $7 \%$ \\
\hline $\begin{array}{l}\text { Oct } \\
2015\end{array}$ & 2919 & 606 & $21 \%$ \\
\hline
\end{tabular}




\section{Getting the student to take action}

The quiz is merely an initial stepping stone to getting the student better prepared for study. Students would ideally take the quiz, identify any areas of weakness, re-consider their choice of MST124 and if necessary submit a change of study. In Scotland, to prompt student action, two Associate Lecturers (tutors) were employed to contact Scottish students who had registered on the October 2015 presentation of MST124 and who had either a low, or no score on the quiz. For all other nations the central Student Support Team (SST), consisting of specialist advisory staff, contacted students with a low score or no score by either email or phone.

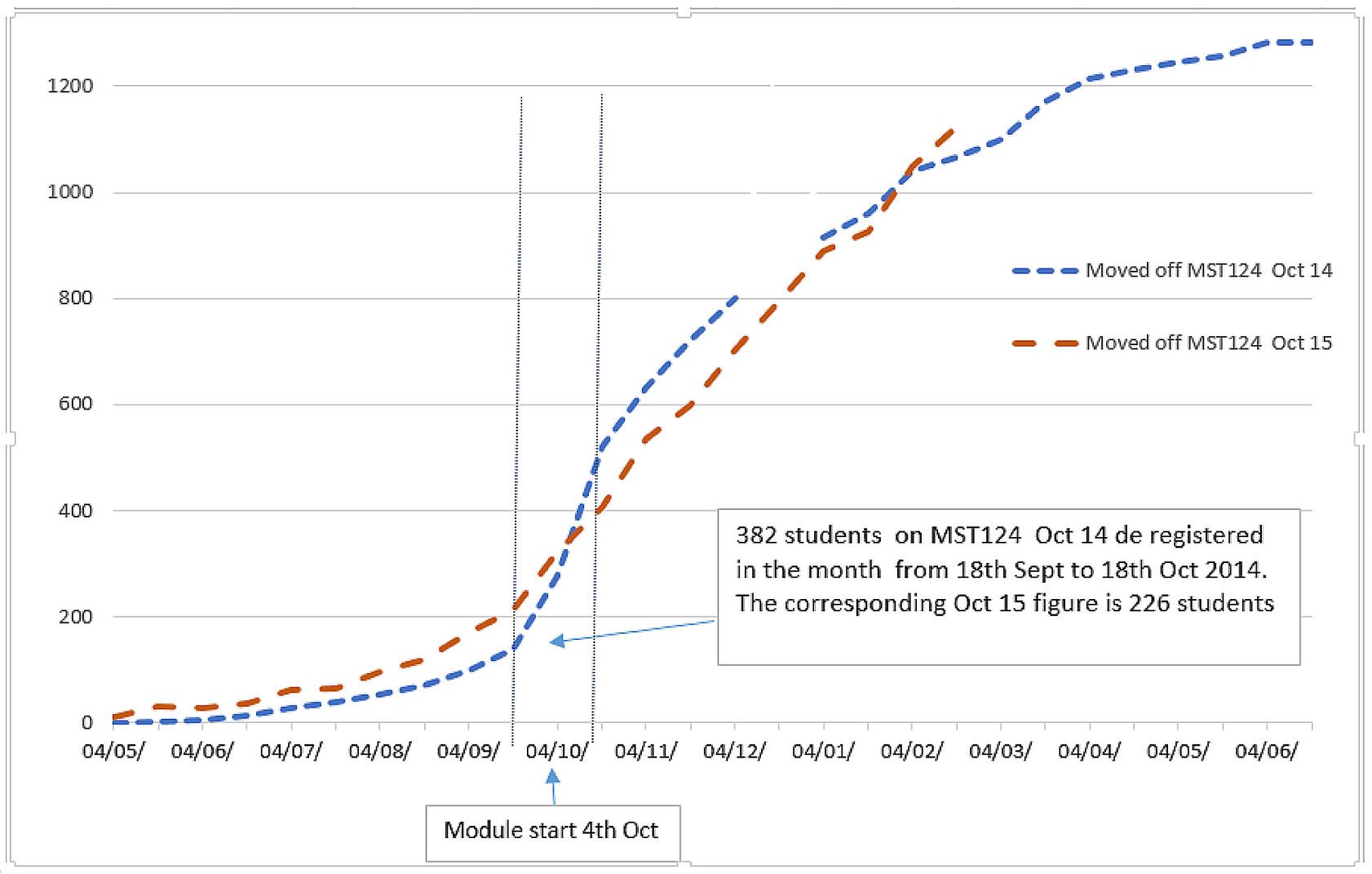

Figure 3: Numbers of students on MST124 Oct 2014 and Oct 2015 who de-register

If students had registered on MST124 and the mathematics involved was unsuitable for them we wanted to see the student withdraw from the module before module start. We also wanted the students who remained on MST124 to be better prepared and hence more likely to stay on MST124. So for October 2015 we wanted to achieve more de-registrations, initiated by the Univerisity or the student, before the $4^{\text {th }}$ October module start date and fewer after that date compared to October 2014. Figure 3 indicates that we saw this effect.

There were just over 230 more students on the October 2015 intake for MST124 than there were in the October 2014 intake. We therefore expected there to be more de-registrations (in terms of numbers) for October 2015 and our aim is for there to be a lower percentage who fail to pass the module. The number of de-registrations was in fact lower, as seen in figure 3, until around week 16 of the module although, at that point in the module, in percentage terms it was still lower at $38 \%$ compared to $40 \%$ for the October 2014 cohort. 
Additionally we would have wished to see students transfer to the alternative module MU123 if their qualification route permitted. Here we had little success with only 80 students transferring to MU123 prior to module start compared to 64 in the previous October of 2014.

\section{Reluctance to action advice}

The discussions with students in the early work on this study established a strong reluctance from students to engage with the University's worries about their ability to study successfully on the module. Students with low quiz scores responded to advisors with comments that they "felt confident"; "felt happy with the challenge of MST124"or "planned to get up to speed before October". Similarly students who had not taken the quiz were typically happy to have been contacted but responded along the lines of the student who was recorded as "Student will take the quiz to check any areas he needs to revise, but is confident". This is not an outcome restricted to OUUK or mathematics diagnostic tests. Batchelor (2004), in relation to new Pharmacy undergraduates using diagnostic maths quizzes, observed that "...students for whom the tests were designed, those with lower mathematical background knowledge, were not using these facilities".

The psychological phenomenon known as Cognitive Dissonance could be one explanation for students not taking the quiz, taking it and ignoring the results or not heeding advice based on quiz results. Cognitive dissonance (Freily and Kothe 2013) demonstrates that once a "difficult to make" decision is made, it becomes fixed and it is difficult to undo. The decision maker actively avoids seeking out or hearing contradictory information as this makes them very uncomfortable. Preventing a student making the wrong initial decision about which mathematics module to study in the first place, and therefore becoming resistant to information or advice, is critical.

For those students who cannot be encouraged to take the quiz and, as necessary, take on additional study to address areas of difficulty or consider a move to MU123 there is another potential intervention point with the students' tutor (Associate Lecturer). The students' quiz scores, where known, where placed into the electronic set of information available to Associate Lecturers about their students. This pack of information becomes available around 2- 4 weeks before MST14 starts. The Associate Lecturer might be able to encourage any of their students for whom there is no quiz score to take the quiz from the internal site. If any of their students have a low quiz score then the Associate Lecturer will be able to discuss, in advance of the start of MST124, additional preparatory resources to help the student succeed.

\section{Conclusions}

The pass rate for students who have done the "Are you ready for MST124" diagnostic quiz is around $60 \%$ whilst for those who have not done the quiz it is $40 \%$. Taking the quiz captures a willingness on the part of student to engage early with their mathematical study; getting a good score on the quiz indicates that the student already has sufficient mathematical knowledge to be well placed for successful study of the module. The simple act of taking the quiz is statistically a much stronger predictor of success than the score.

The quiz merely represents the first step in the task of trying to ensure that students are adequately prepared for their study. For some students there is a possibility that their qualification pathway would enable them to study MU123 and this may therefore be a more appropriate choice. Some students may already have studied MU123 or their qualification may require them to study MST124 but we have a wealth of materials available to support such students not least the support all students get directly from their personal tutor. 
Students welcomed the contact from advisors at an early stage but very few followed up the discussion by either taking the diagnostic quiz or moving to another module where this was available. A possibility, despite issues around ethics and creating psychological discomfort, is to design an intervention based around success rate information to jolt students into using the quiz to establish their readiness for study.

\section{References}

Batchelor, H., 2004. The importance of a Mathematics Diagnostic Test for Incoming Pharmacy Undergraduates. Pharmacy Education, 4(2), pp.69-74.

Calvert, C., 2014. Developing a model and applications for probabilities of student success: a case study of predictive analytics. Open Learning, 29(2), pp.160-173.

Donavan, D. and Loch, B., 2013. Closing the feedback loop: engaging students in large first-year mathematics test revision sessions using pen-enabled screens. International Journal of Mathematical Education in Science and Technology, 14(1), pp.1-13.

Engineering Council, 2000. Measuring the Mathematics Problem. [pdf] London: Engineering Council. Available at:

http://www.engc.org.uk/engcdocuments/internet/Website/Measuring\%20the\%20Mathematic\%20Pr oblems.pdf [Accessed 24 March 2016]

Freijy, T. and Kothe, E., 2013. Dissonance-based interventions for health behaviour change: A systematic review. British Journal of Health Psychology,18(2), pp.310-337.

Lockwood, F., 1989. The evaluation of Open University preparatory packages, Open Learning: The Journal of Open, Distance and e-Learning, 4(2), pp.43-46.

OUUK, 2016. Maths Choices [online] Available at: http://mathschoices.open.ac.uk/are-you-readyquizzes/mst124-quiz [Accessed: 24 March 2016]

Simpson, O., 2006. Predicting student success in open and distance learning. Open learning, 21(2), pp.125-138

Slade, S and Prinsloo, P., 2013. Learning analytics: ethical issues and dilemmas. American Behavioural Scientist, 55(10) pp.1509-1528. 